\title{
Correlation between Cerebral Blood Flow, Somatosensory Evoked Potentials, CT Scan Grade and Neurological Grade in Patients with Subarachnoid Hemorrhage
}

\author{
M. Fazl, D.A. Houlden and K. Weaver
}

\begin{abstract}
Cerebral blood flow (CBF) and central conduction time (CCT) were recorded from 58 subarachnoid hemorrhage patients and from 49 age-matched controls. CBF was calculated following Xenon inhalation and CCT was determined from somatosensory evoked potentials (SSEP's) following median nerve stimulation. Each patient had a CT scan on the day of admission which was graded from I-IV. CBF, CCT and neurological grade (Hunt and Hess classification) were concomitantly recorded 1, 4, 7 and 14 days after subarachnoid hemorrhage. Mean CBF was highest in patients with neurological grades I and II $(48.6 \pm 12.3$ and $48.1 \pm 10.3 \mathrm{ml} / 100 \mathrm{gm} / \mathrm{min}$ respectively $)$ and lowest in patients with neurological grade IV $(37.3 \pm 9.6 \mathrm{ml} / 100 \mathrm{gm} / \mathrm{min})$. Patients in neurological grade I or II had mean CBF and CCT measurements that were significantly different from those obtained from patients in neurological grade IV $(\mathrm{P}<0.05)$. Neurological grade and CT scan grade correlated with CBF $(P<0.0001)$ better than CCT $(P=0.015)$. Unexpectedly low CBF's from patients in neurological grades II and III ( $<37$ and $<31 \mathrm{ml} / 100 \mathrm{gm} / \mathrm{min}$ respectively) failed to significantly prolong CCT suggesting CCT is unable to detect marginal ischemia. A significant correlation between CBF and CCT occurred only when CBF was $<30 \mathrm{ml} / 100 \mathrm{gm} / \mathrm{min}(\mathrm{R}=$ $0.75, \mathrm{P}=0.05$ ). It appears that prolonged CCT is associated with a drop in CBF only when CBF drops below a certain threshold.
\end{abstract}

\begin{abstract}
RÉSUMÉ: Corrélation entre le flot sanguin cérébral, les potentiels évoqués somesthésiques, l'évaluation par CT scan et l'évaluation neurologique chez les patients avec hémorragie sous-arachnoïdienne Le flot sanguin cérébral (FSC) et le temps de conduction central (TCC) ont été enregistrés chez 58 patients avec hémorragie sous-arachnoïdienne et chez 49 témoins appariés pour l'âge. Le FSC a été calculé après inhalation de Xénon et le TCC a été déterminé par les potentiels évoqués somesthésiques (PES) après stimulation du nerf médian. Le CT scan, que chaque patient a subi le jour de l'admission, a été coté de I à IV. Le FSC, le TCC et l'évaluation neurologique (Classification de Hunt et Hess) ont été enregistrés $1,4,7$ et 14 jours après l'hémorragie sous-arachnoïdienne. Le FSC moyen était le plus élevé chez les patients dont la cote neurologique était de I et II $(48.6 \pm 12.3$ et $48.1 \pm 10.3 \mathrm{ml} / 100 \mathrm{gm} / \mathrm{min}$ respectivement et le plus bas chez les patients dont la cote neurologique était de IV $(37.3 \pm 9.6 \mathrm{ml} / 100 \mathrm{gm} / \mathrm{min})$. Les patients dont la cote neurologique était de I ou II avaient un FSC et un TCC qui étaient significativement différents de ceux obtenus chez les patients dont la cote neurologique était de IV $(\mathrm{P}<0.05)$. La cote neurologique et la cote du CT scan avaient une meilleure corrélation avec le FSC $(\mathrm{P}<0.0001)$ qu'avec le TCC $(\mathrm{P}=0.015)$ Etonnamment, un FSC faible chez les patients dont la cote neurologique était de II et III $(<37$ et $<31 \mathrm{ml} / 100 \mathrm{gm} / \mathrm{min}$ respectivement) ne provoquait pas de prolongement significatif du TCC suggérant que le TCC est incapable de détecter une ischémie marginale. une corrélation significative entre le FSC et le TCC était observée seulement quand le FSC était $<30 \mathrm{ml} / 100 \mathrm{gm} / \mathrm{min}(\mathrm{R}=0.75$, $\mathrm{P}$ $=0.05)$. Il semble qu'un TCC prolongé est associé à une chute du FSC seulement quand le FSC s'abaisse sous un certain seuil.
\end{abstract}

Can. J. Neurol. Sci. 1991; 18: 453-457

Severe vasospasm is an important cause of delayed ischemic neurological deficits which develop after subarachnoid hemorrhage. 1,2,3 Patients with diffuse vasospasm after subarachnoid hemorrhage have neurological deficits related to low cerebral blood flow (CBF) and patients without delayed ischemic neurological deficits have higher CBF's. ${ }^{4,5}$ In contrast, some patients with subarachnoid hemorrhage may appear to be perfectly well even when they have marginal ischemia with low CBF.6,7

From the Sunnybrook Health Science Centre, Division of Neurosurgery, University of Toronto

Received November 26, 1990. Accepted in final form April 19, 1991

Reprint requests to: M. Fazl, M.D., Division of Neurosurgery, Sunnybrook Health Science Centre, 2075 Bayview Avenue, Ste. A-138, Toronto, Ontario, Canada M4N 3M5 
Operative manipulation of cerebral blood vessels during clipping of an aneurysm in these patients could precipitate major ischemia. Accordingly, we think it is advantageous to use CBF to determine the state of cerebral perfusion in preoperative subarachnoid hemorrhage patients so the timing of surgery may be optimally planned. Unfortunately, CBF equipment is expensive and not available in most hospitals.

Prolongation of central conduction time (CCT) (as measured by somatosensory evoked potentials (SSEP's) correlates with neurological grade in baboons ${ }^{8}$ and humans 9,10 with subarachnoid hemorrhage. CCT prolongation appears to be directly proportional to CBF diminution when CBF drops below approximately $30 \mathrm{ml} / 100 \mathrm{gm} / \mathrm{min}$ in humans. ${ }^{9}$

In this study we examined the relationship between CCT, CBF, CT scan and neurological grade to determine if CCT can replace $\mathrm{CBF}$ in identifying patients with marginal ischemia who may appear relatively well but have unexpectedly low CBF's.

\section{Materials ANd Methods}

\section{Cerebral Blood Flow (CBF)}

CBF was measured using the Novo inhalation cerebrograph (Nova Diagnostic Systems, Denmark). All the studies were performed using the Xenon-133 inhalation technique. Mean CBF was determined for each hemisphere by 16 collimated scintillation detectors ( 8 detectors per hemisphere) placed perpendicular to the saggital plane of the skull. A dose of $30 \mathrm{mCi}$ of Xenon 133 was used for each study. The CBF was determined by Obrist's model. 13 The initial slope index (ISI) was used as the standard measure of CBF because it is not affected by changes in the relative weight of fast (grey matter) and slow (white matter) CBF compartments of the brain which may be in a state of flux in a pathological brain. ${ }^{14} \mathrm{CBF}$ was measured $1,4,7$ and 14 days after subarachnoid hemorrhage and within 1 day prior to and after surgery. A mean CBF (ISI) of $56.6 \mathrm{ml} / 100 \mathrm{gm} / \mathrm{min}$ with a standard deviation of $9 \mathrm{ml} / 100 \mathrm{gm} / \mathrm{min}$ was obtained from 49 normal subjects between the ages of 20 and 64 .

\section{Central Conduction Time (CCT)}

The technique used to record somatosensory evoked potentials (SSEP) was similar to that used by Hume and Cant 11,12 and Symon et al. ${ }^{4}$ The left and right median nerves were stimulated at the wrist with a stimulus intensity 1.5-2 times the intensity necessary to evoke a visible thenar muscle twitch with a stimulus duration of $0.2 \mathrm{msec}$ and a stimulus rate of $3.1 \mathrm{~Hz}$. SSEP recordings were obtained from $10 \mathrm{~mm}$ gold-plated EEG cup disc electrodes placed on the surface of the skin and from Grass subdermal needle electrodes on the scalp. Skin/electrode impedance was kept below $5 \mathrm{~K} \Omega$. The location of the four recording electrode pairs (G1-G2) for the median nerve SSEP were:

1) scalp overlying the contralateral somatosensory cortex (C3' or C4') - contralateral Erbs point (EP contra); 2) ipsilateral Erbs point (EP ipsi) - Fpz; 3) C2 spinous process (Cv2) - Fpz and 4) C3' or C4' - Fpz.

The analogue input from each recording pair was amplified by Grass model 12A5 amplifiers with a grain of 100,000 and a bandpass of $3-3000 \mathrm{~Hz}$ before being averaged by a NEC advanced personal computer with a Datacon A-D board (ClarkDavis Medical Systems, London, Ontario, Canada). The sampling rate of the system was $14.6 \mathrm{KHz}$ on each channel. Analysis time was $70 \mathrm{msec}$ on all four channels though the display time was $35 \mathrm{msec}$ for all channels with the exception of channel 4 which had a dual display time of $35 \mathrm{msec}$ and 70 msec. Each 4 channel average contained at least 500 responses. A minimum of two 4-channel averages (epochs) were superimposed for waveform reproducibility.

CCT was determined from the interpeak latency (IPL) between the $\mathrm{P} / \mathrm{N} 13$ waveform recorded from the $\mathrm{C} 2$ spinous process ( $\mathrm{Cv} 2)$ - Fpz and the N20 waveform recorded from the scalp (C3' or C4'-Fpz). CCT was measured within 1 hour of CBF testing 1, 4, 7 and 14 days after subarachnoid hemorrhage. A normal mean CCT of 5.75 msec with a standard deviation of $0.6 \mathrm{msec}$ was determined from 36 normal subjects between the ages of 20 and 64 .

\section{CT Scan Grade}

Each patient had a CT scan of the brain on the first day of admission which was classified according to the thickness of blood in the subarachnoid space. ${ }^{2}$ Patients in CT scan group I had no detectible blood in the subarachnoid space. Group II patients had diffuse deposition of thin layers of blood with all vertical layers of blood (interhemispheric fissure, insular cistern, ambiant cistern) less than $1 \mathrm{~mm}$ thick. Group III patients had localized clots and/or vertical layers of blood clot more than 1 mm thick. Group IV patients had diffuse and/or no subarachnoid blood with intracerebral or intraventricular clots.

\section{Neurological Grade}

The Hunt and Hess neurological grading system for subarachnoid patients ${ }^{10}$ was used to grade neurological status at the time of each CBF and CCT measurement.

\section{Statistical Methods:}

A oneway analysis of various (ANOVA) (SAS program, SAS Institute, Carey, N.C.) was used to determine the relationship of CBF and CCT to CT scan grade and neurological grade. A oneway ANOVA with Tukey pairwise comparison was used to look for differences between neurological grades when comparing them on mean CBF and mean CTT. A parallel set of nonparametric statistical tests (Kruskal/Wallis) were done to corroborate the ANOVA results.

A Pearson product moment correlation was calculated for $\mathrm{CBF}$ and $\mathrm{CCT}$. Then, $\mathrm{CBF}$ was divided into three ranges $(<30$, $31-40,>40$ ) and a Pearson correlation for CBF and CCT was repeated for each range. A rank order correlation (Spearman) was performed to look for a relationship between neurological grade and CT Scan grade.

A t-test was performed to compare mean CCT from patients in neurological grade I whose CBF's were $>36.3$ and $<36.3$ $\mathrm{ml} / 100 \mathrm{gm} / \mathrm{min}$. The CBF cutpoint of $36.3 \mathrm{ml} / 100 \mathrm{gm} / \mathrm{min}$ was arbitrarily determined by taking the mean CBF from neurological grade I $(48.6 \mathrm{ml} / 100 \mathrm{gm} / \mathrm{min})$ - 1 standard deviation $(12.3$ $\mathrm{ml} / 100 \mathrm{gm} / \mathrm{min}$ ). A similar t-test was performed on CCT for neurological grade II patients (CBF cutpoint $=37.8 \mathrm{ml} / 100 \mathrm{gm} / \mathrm{min}$ ) and neurological grade III patients $($ CBF cutpoint $=31.4$ $\mathrm{ml} / 100 \mathrm{gm} / \mathrm{min}$ ). 


\section{RESULTS}

CBF, CCT, CT scan grade and neurological grade were obtained from 50 subarachnoid hemorrhage patients $(29$ male, 29 female) who were between 19 and 75 years of age (mean age $=46.5$ years). All patients underwent cerebral angiography and aneurysms were detected in 49 patients. Patients who had no blood on the initial CT scan study had a lumbar puncture to prove the presence of subarachnoid hemorrhage.

\section{Neurological Grade and CBF}

The relationship between neurological grade and mean CBF was evaluated in all patients. There were 139 CBF measurements from 58 patients. Oneway analysis of variance (ANOVA) showed $\mathrm{CBF}$ significantly correlated with neurological grade ( $\mathrm{F}$ $(3,135)=9.73, \mathrm{P}<0.0001)$. Many patients who deteriorated to a higher neurological grade had a concomitant decrease in CBF and the reverse was also true (Figure 1). Mean CBF was highest in patients with neurological grade I and II (48.6 \pm 12.3 $\mathrm{ml} / 100 \mathrm{gm} / \mathrm{min}$ and $48.1 \pm 10.3 \mathrm{ml} / 100 \mathrm{gm} / \mathrm{min}$ respectively) and lowest in neurological grade IV patients $(\mathrm{CBF}=37.3 \pm 9.6$ $\mathrm{ml} / 100 \mathrm{gm} / \mathrm{min}$ ). Mean CBF's from neurological grades I and II were not significantly different and there was also no significant difference between mean CBF's from neurological grades III and IV. In contrast, mean CBF's in neurological grades III and IV were significantly different from mean CBF's in neurological grades I and II ( $\mathrm{P}<0.05$, Figure 1$)$.

\section{Neurological Grade and CCT}

There were 122 CCT measurements from 58 patients. The ANOVA indicated a relationship between neurological grade and $\mathrm{CCT}(\mathrm{F}(3,118)=23.63, \mathrm{P}=0.015)$. CCT tended to become

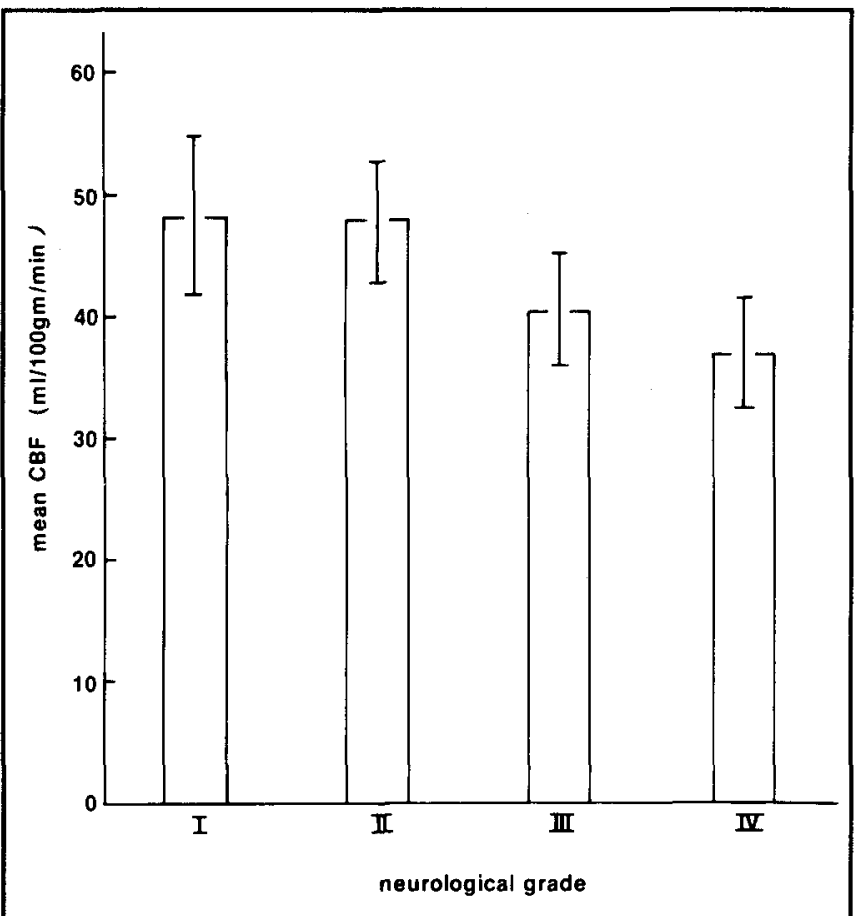

Figure I - Mean cerebral blood flow (CBF) with one standard error of the mean are shown for each neurological grade. Mean CBF's in neurological grades I and II were significantly different from mean $C B F$ 's in neurological grades III and $I V(P<0.05)$. gradually prolonged with deterioration of neurological grade (Figure 2). Nevertheless, only the mean CCT's from neurological grades I and IV were significantly different $(\mathrm{P}<0.05)$. Mean CCT was $6.3 \pm 1.05 \mathrm{~ms}$ in neurological grade IV and $5.42 \pm$ $0.49 \mathrm{~ms}$ in neurological grade I.

Patients in neurological grades II and III with CBF's $<37.8$ and $<31.4 \mathrm{ml} / 100 \mathrm{gm} / \mathrm{min}$ respectively did not have significantly longer CCT's than patients in the same neurological grades with higher CBF's. There were not enough patients in neurological grade I with CBF's below the cutpoint $(36.3 \mathrm{ml} / 100 \mathrm{gm} / \mathrm{min})$ for meaningful statistical analysis in this grade.

\section{Neurological Grade and CT Scan Grade}

There was a significant relationship between CT scan grade and neurological grade ( $R$ ho $=0.53, \mathrm{P}<0.0001, \mathrm{~N}=140$ ). Patients with more blood in the subarachnoid space and/or ventricles tended to have a higher neurological grade.

\section{CBF and CCT}

The relationship between CBF and CCT was examined in both cerebral hemispheres for a total of 261 studies. There was a relationship between CBF and CCT $(R=-0.213, P=0.019)$ but CCT significantly correlated with CBF only when CBF was $<30 \mathrm{ml} / 100 \mathrm{gm} / \mathrm{min}(\mathrm{R}=-0.75, \mathrm{P}=0.05)$ as in some neurological grade IV patients.

\section{CBF and CT Scan Grade}

There was a significant difference in the mean CBF's from patients in CT scan grade I and II and CT scan grades III and IV. In contrast, mean CBF's from patients in CT scan grades I and II were significantly different from the mean CBF's from patients in CT scan grades III and IV $(P<0.05)$. ANOVA

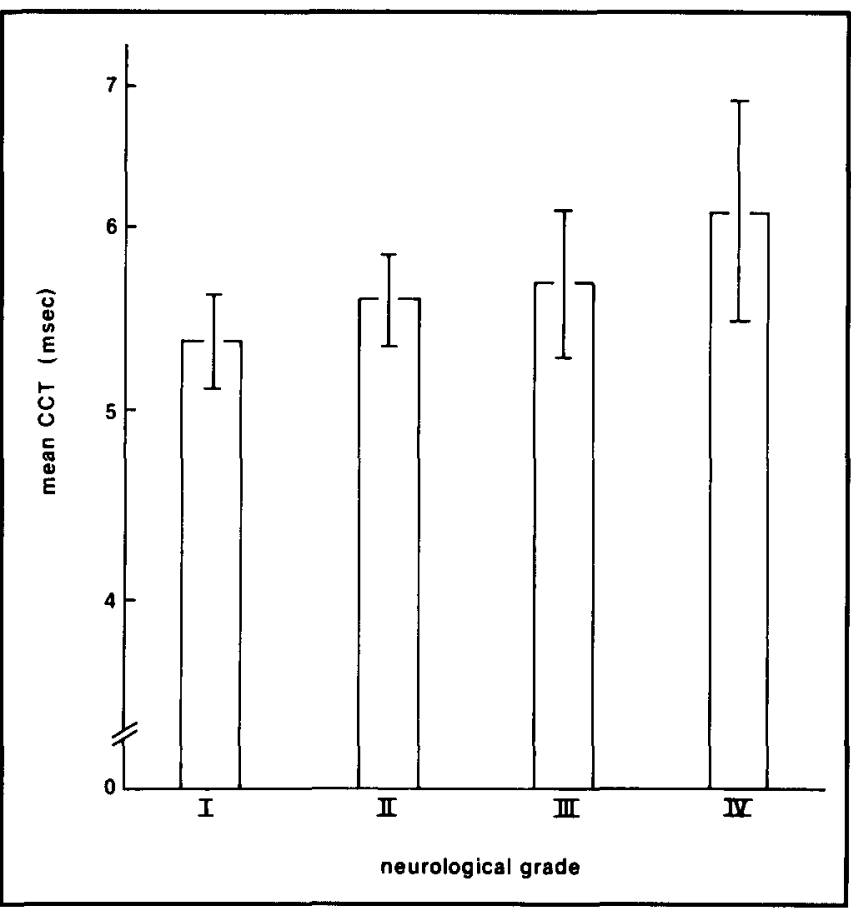

Figure 2 - Mean central conduction time (CCT) with one standard error of the mean are shown for each neurological grade. Mean $C C T$ in neurological grade $I V$ was significantly different from mean $C C T$ 's in neurological grade I, II and III $(P<0.05)$. 
revealed CBF was significantly related to $\mathrm{CT}$ scan grade ( $\mathrm{F}$ $(3,135)=9.06, P<0.0001$, Figure 3$)$.

\section{CCT and CT Scan Grade}

Mean CCT's for each CT scan grade were not significantly different (Figure 4).

\section{Discussion}

Despite our inability to demonstrate an overall correlation between CBF and SSEP central conduction time in patients with subarachnoid hemorrhage, the relationship between CBF and SSEP's and the role of CBF in maintaining brain function has been described in animal experiments. ${ }^{15-18}$ CBF's below approximately $16 \mathrm{~mm} / 100 \mathrm{gm} / \mathrm{min}$ caused the cortical SSEP amplitude and latency to change, CBF's of approximately 12 $\mathrm{mm} / 100 \mathrm{gm} / \mathrm{min}$ caused the SSEP to disappear and, in baboons, a drop in CBF below that required for the SSEP to disappear was necessary for permanent neurological deficit. According to Astrup et al,17 the disappearance of the SSEP "could not be explained by the release of intracellular potassium, nor was it critically dependent on cortical pH. However, the massive release of intracellular potassium was, by itself, critically dependent on CBF." They described a dual threshold in ischemia for neuronal function with the threshold for release of intracellular potassium being clearly lower than the threshold for complete electrical failure of the cell which supports the concept of an ischemic period during which the neuron remains structurally intact but functionally inactive. They concluded that "increased

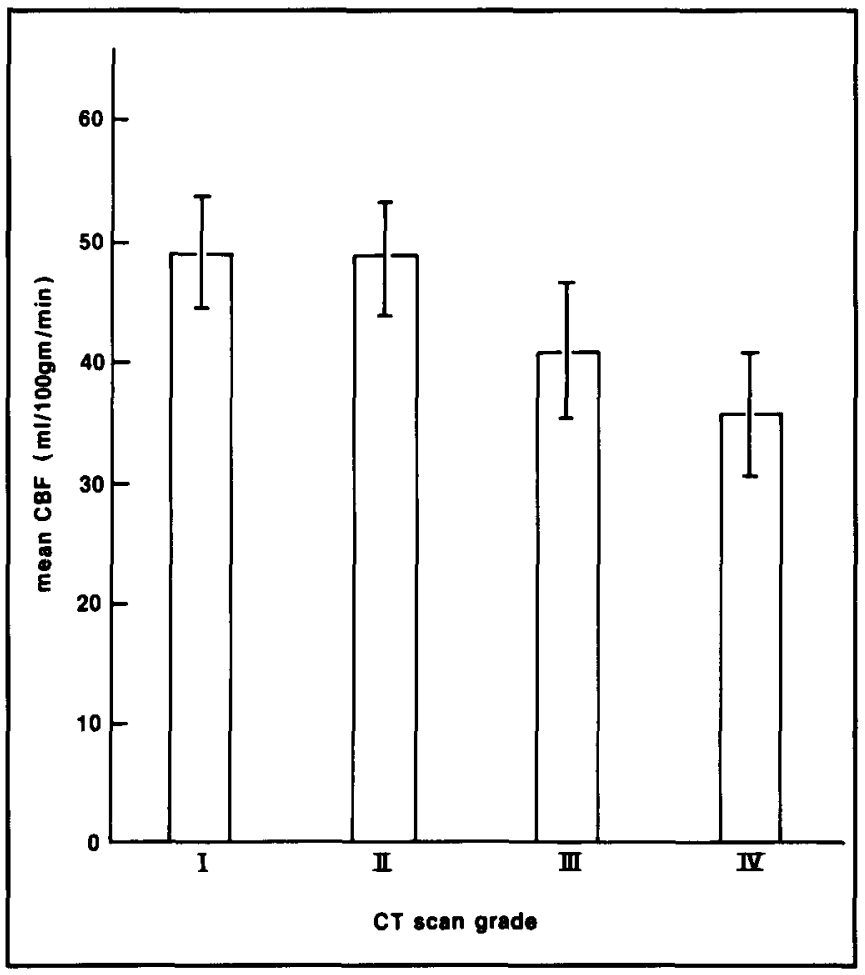

Figure 3 - Mean cerebral blood flow (CBF) with one standard error of the mean are shown for each $C T$ scan grade. Mean $C B F$ 's in $C T$ scan grades III and $I V$ were significantly different from the mean $C B F$ 's in $C T$ scan grades I and II $(P<0.05)$.
CBF, if sufficient, may normalize extracellular potassium activity as well as pH and restore the SSEP" and, we might add, restore neuronal function.

In our study we used the SSEP central conduction time (CCT) to reflect the integrity of the large fibre sensory system within the brain. Rosenstein et $\mathrm{l}^{9}{ }^{9}$ demonstrated a threshold relationship between $\mathrm{CBF}$ and CCT in humans: little change in CCT was noted at flows $>30 \mathrm{ml} / 100 \mathrm{gm} / \mathrm{min}$ but, at flows below 30 , CCT became increasingly prolonged with the degree of prolongation proportional to the degree of blood flow diminution. Similarly, we found that when CBF was divided into three ranges $(<30,31-40,>40)$, a significant correlation between CBF and CCT existed only in patients whose CBF was $<30$ $\mathrm{ml} / 100 \mathrm{gm} / \mathrm{min}$ although a directly proportional relationship was not proven in this range. Lack of correlation between CBF and CCT in patients with CBF's between $31-40$ and $>40 \mathrm{ml} / 100 \mathrm{gm} /$ min suggests one cannot predict $\mathrm{CBF}$ from CCT when $\mathrm{CBF}$ is above $30 \mathrm{ml} / 100 \mathrm{gm} / \mathrm{min}$. Furthermore, patients in neurological grades II and III had no significant difference in mean CCT despite a significant difference in mean CBF between the two grades suggesting CBF is more sensitive than CCT to marginal ischemia and moderate neurological deficits.

Perhaps other ways of measuring CCT may be more informative in patients with subarachnoid hemorrhage. For example, in our study we used a small number of scalp and non-cephalic recording electrode pairs so it was difficult to determine if subthalamically or thalamically generated N18 activity contaminated N20 peak latency determination, seeing as both negative peaks may occur at the same time. ${ }^{20,21}$ This contamination was

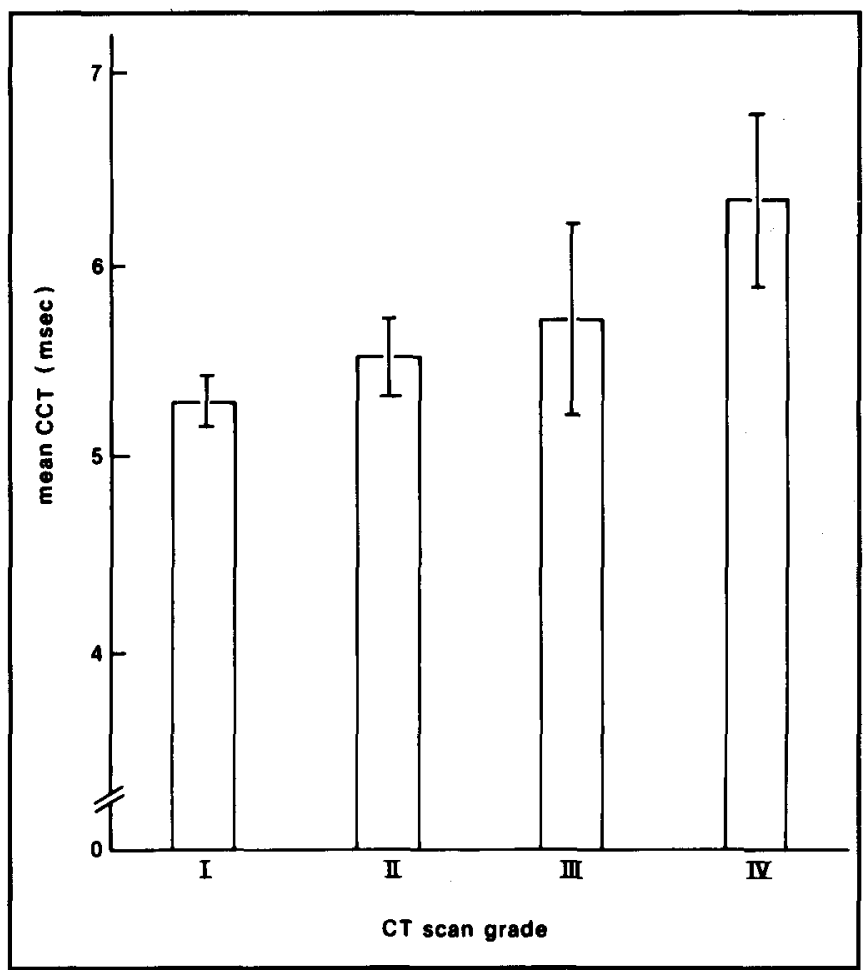

Figure 4-Mean central conduction time (CCT) with one standard error of the mean are shown for each CT scan grade. Mean CCT's were not significantly different between CT scan grades. 
unlikely however because we recorded N20 from C3' or C4' Fpz (scalp-scalp) which should have cancelled most of N18 because $\mathrm{N} 18$ is seen simultaneously at both scalp recording sites (C3' or C4' and Fpz). In contrast, N20 is predominently seen at one recording site ( $\mathrm{C}^{\prime}$ ' or $\mathrm{C}^{\prime}$ ') making it the prominent negative peak. Another way to measure CCT could be from the onset of waveforms instead of their peaks. ${ }^{22}$ Future studies should be done to determine the value of these alternative methods of measuring CCT.

Subarachnoid hemorrhage patients with vasospasm and low CBF's may have impaired brain autoregulation and be intolerant to intra-operative hypotension and operative manipulation of cerebral blood vessels during clipping of an aneurysm. Some researchers suggest that patients with CBF's $<35$ $\mathrm{ml} / 100 \mathrm{gm} / \mathrm{min}$ may have brain ischemia related to vasospasm and be at surgical risk even though some of these patients may appear to be well or have only minor neurological deficits (silent spasm syndrome). ${ }^{7}$ It appears that $\mathrm{CCT}$, the way we measured it, would be ineffective in detecting patients with CBF's between $30-35 \mathrm{ml} / 100 \mathrm{gm} / \mathrm{min}$. In fact, we demonstrated that patients with moderate neurological deficits (neurological grades II and III) and unexpectedly low flows $(<37.8$ and $<31.4 \mathrm{ml} / 100 / \mathrm{min}$ respectively) had no significant difference in mean CCT when compared to the mean CCT from patients in the same neurological grade with higher CBF's. This necessitates CBF testing for subarachnoid hemorrhage patients prior to surgical clipping of their aneurysm(s).

Fisher et $\mathrm{al}^{2}$ described a positive correlation between the amount and location of subarachnoid blood and the degree of vasospasm in patients with subarachnoid hemorrhage. Consequently, it was not surprising for us to find a correlation between $\mathrm{CT}$ scan grade and neurological grade, CT scan grade and CBF, and CBF and neurological grade.

\section{Conclusions}

1. CCT is not useful in detecting unexpectedly low CBF's in patients with neurological grade II or III.

2. CBF correlated with CCT when CBF was $<30$ $\mathrm{ml} / 100 \mathrm{gm} / \mathrm{min}$ but did not correlate with $\mathrm{CCT}$ when $\mathrm{CBF}$ was $31-40$ or $>40 \mathrm{ml} / 100 \mathrm{gm} / \mathrm{min}$.

3. Our findings suggest a causal relationship between the amount of blood in the subarachnoid space, CBF and neurological grade.

\section{ACKNOWLEDGEMENTS}

The authors would like to thank Marko Katic for statistical analysis and Susan Shanab for preparation of the manuscript. This research was funded by the Sunnybrook Research Foundation.

\section{REFERENCES}

1. Fisher CM, Robertson GH, Ojemann RG. Cerebral vasospasm with ruptured saccular aneurysm - The clinical manifestations. Neurosurgery $1977 ; 1: 245-248$.

2. Fisher CM, Kistler JP, Davis JM. Relation of cerebral vasospasm to subarachnoid hemorrhage visualized by computer tomographic scanning. Neurosurgery 1980; 6: 1-9.
3. Ishii R. Regional cerebral blood flow in patients with ruptured intracranial aneurysm. J Neurosurg 1979; 50: 587-594.

4. Symon L, Hargadine J, Zawirski M, et al. Central conduction time as an index of ischemia in subarachnoid hemorrhage. J Neurol Sci 1979; 44: 95-103.

5. Yamakami I, Isobe K, Yamaura A, et al. Vasospasm and regional cerebral blood flow (rCBF) in patients with ruptured intracranial aneurysm: Serial rCBF studies with the xenon-133 inhalation method. Neurosurgery 1983; 13: 394-401.

6. Drake CG. Post-operative arterial spasm. In: Wilkins RH, ed. Cerebral Arterial Spasm: Proceedings of the Second International Workshop. Baltimore: Williams \& Wilkins, 1980 , 180: $435-437$

7. Ferguson GG, Farrar JK, Meguro $K$, et al. Serial measurements of $\mathrm{CBF}$ as a guide to surgery in patients with ruptured intracranial aneurysms. J Cereb Blood Flow Metab 1981; 1 (suppl. 1): S518-s.

8. Hargadine JR, Branston NM, Symon L. Central conduction time in primate brain ischemia - a study in baboons. Stroke 1980; 11 : 637-62.

9. Rosenstein J, Wang ADJ, Symon L, et al. Relationship between hemispheric cerebral blood flow, central conduction time, and clinical grade in aneurysmal subarachnoid hemorrhage. J Neurosurg 1985; 62: 25-30.

10. Hunt WE, Hess RM. Surgical risk related to time of intervention in the repair of intracranial aneurysm. J Neurosurg 1968; 28: 14-20.

11. Hume AL, Cant BR. Conduction time in central somatosensory pathways in man. Electroencephalogr Clin Neurophysiol 1978; 45: 361-375.

12. Hume AL, Cant BR, Shaw NA. Central somatosensory conduction time in comatose patients. Ann Neurol 1979; 5: 379-384.

13. Obrist WD, Thompson HK Jr, Want HS, et al. Regional cerebral blood flow estimated by xenon-133 inhalation. Stroke 1975; 6: 245-256.

14. Risberg J, Ali Z, Wilson EM, et al. Regional cerebral blood flow by 133 xenon inhalation. Stroke $1975 ; 6: 142-148$.

15. Branston NM, Symon L, Crockard HA, et al. Relationship between the cortical evoked potential and local cortical blood flow following acute middle cerebral artery occlusion in the baboon. Exp Neurol 1974; 45: 195-208.

16. Heiss WD, Hayakawa T, Waltz AG. Cortical neuronal function during ischemia. Effects of occlusion of one middle cerebral artery on single-unit activity in cats. Arch Neurol 1976; 33: 813-820.

17. Astrup J, Symon L, Branston NM, et al. Cortical evoked potential and extracellular $\mathrm{K}+$ and $\mathrm{H}+$ at critical levels of brain ischemia. Stroke 1977; 8: 51-57.

18. Dowman R, Boisvert DP, Gelb AW, et al. Changes in the somatosensory evoked potential during and immediately following temporary middle cerebral artery occlusion predict somatosensory cortex ischemic lesions in monkeys. J Clin Neurophysiol 1990; 7: 269-281.

19. Mauguiere F, Desmedt JE, Courjon J. Neural generators of N18 and P14 far-field somatosensory evoked potentials studied on patients with lesion of thalamus or thalamo-cortical radiations. Electroencephalogr Clin Neurophysiol 1983; 56: 283-292.

20. Urasaki E, Wada, S, Kadoya C, et al. Origin of scalp far-field N18 of SSEP's in response to median nerve stimulation. Electroencephalogr Clin Neurophysiol 1990; 77: 39-51.

21. Desmedt JE, Cheron G. Non-cephalic reference recording of early somatosensory potentials to finger stimulation in adult or aging normal man: differentiation of widespread N18 and contralateral N20 from the prerolandic P22 and N30 components. Electroencephalogr Clin Neurophysiol 1981; 52: 553-570.

22. Zegers de Beyl D, Delberghe X, Herbaut AG, et al. The somatosensory central conduction time: Physiological considerations and normative data. Electroencephalogr Clin Neurophysiol 1988; 781: 17-26. 